\title{
Understanding the impact of simulated patients on health care learners communication skill: A systematic review
}

Jessica Kaplonyi ${ }^{1}$

Kelly-Ann Bowles ${ }^{2}$

Debra Nestel ${ }^{3}$

Debra Kiegaldie $^{4}$

Stephen Maloney

Terry Haines 5

Cylie Williams ${ }^{1,5}$

${ }^{1}$ Peninsula Health, Allied Health, 2 Hastings Rd, Frankston, VIC, 3199, Australia

${ }^{2}$ Monash University, Department of Community Emergency Health and Paramedic Practice, McMahons Rd, Frankston, VIC, 3199, Australia

${ }^{3}$ Monash University, Faculty of Medicine, Nursing \& Health Sciences, Wellington Rd, Clayton, VIC 3168

${ }^{4}$ Holmesglen Institute \& Healthscope Hospitals, Faculty of Health Science, Youth \& Community Studies, 488 South Road, Moorabbin, VIC 3148

${ }^{5}$ Monash University, Department of Physiotherapy, McMahons Rd, Frankston, VIC, 3199, Australia

${ }^{6}$ Monash Health, Allied Health Research Unit, Crns Warrigal and Kingston Rds,

Cheltenham, VIC, 3192

\section{Corresponding Author:}

This is the author manuscript accepted for publication and has undergone full peer review but has not been through the copyediting, typesetting, pagination and proofreading process, which may lead to differences between this version and the Version of Record. Please cite this article as doi: $10.1111 /$ medu.13387

This article is protected by copyright. All rights reserved 
Cylie Williams

Peninsula Health, Allied Health, Office for Research,

2 Hastings Rd, Frankston, VIC, 3199, Australia

cyliewilliams@phcn.vic.gov.au

Ph: +61397848100 Fax: +61397848149

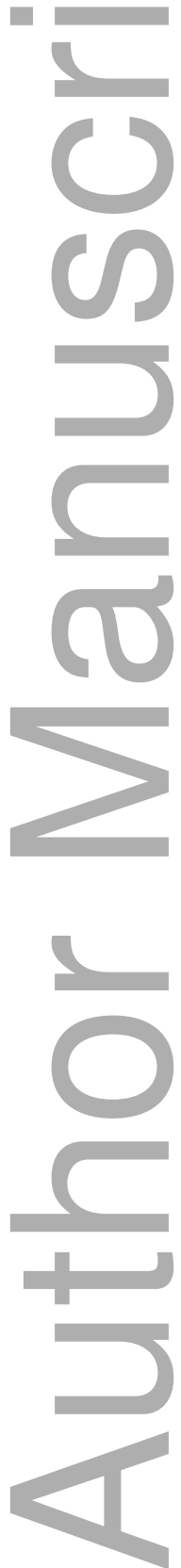

This article is protected by copyright. All rights reserved 


\title{
r. \\ Article type : Medical Education in Review

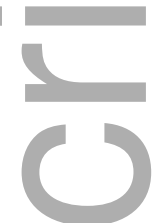 \\ Understanding Impact of simulated patients on health care learners communication skills: A systematic review
}

\begin{abstract}
Background: Effective communication skills are at the core of good healthcare. Simulated patients (SP) are increasingly engaged as an interactive means of teaching, applying, and practising communication skills with immediate feedback. There is a large body of research into the use of manikin-based simulation but a gap exists in the body of research on the effectiveness of SP-based education to teach communication skills that impact patient outcomes. The aim of this systematic review was to critically analyse the existing research investigating whether SP-based communication skills training improves learner-patient communication, how communication skill improvement is measured, and who measures these improvements.
\end{abstract}

Methods: Databases Medline, ProQuest (Health \& Medical Complete, Nursing and Allied Health Source), and CINAHL (EBSCOhost) and ERIC were searched for articles which investigated the effects of SP-based education on the communication skills of medical, nursing, and allied health learners.

Results: There were 60 studies included in the review. Only two studies reported direct patient outcomes, one reporting some negative impact, and no studies included an economic analysis. Many studies reported statistically significant third party ratings of 
improved communication effectiveness following SP-based education, however studies were unable to be pooled for meta-analysis due to outcome collection methods. There were a small number of studies comparing SP to no training at all and there were no differences between communication skills, contradicting the results from studies reporting benefits. Of the 60 studies included for analysis, 54 (90\%) met the minimum quality score of 7/11 with four articles (7\%) scoring 11/11.

Conclusion: SP-based education is widely accepted as a valuable and effective means of teaching communication skills but there is limited evidence of how this translates to patient outcomes and no indication of economic benefit for this type of training over another method.

\section{Introduction}

Effective communication skills are at the heart of safe clinical care. Simulation has emerged as a core educational strategy for skills development in medical, nursing, and allied health professions education. Simulation can allow for learners to develop skills and learn from their mistakes in a safe environment where they will not be penalised, and where no harm can come to patients. Simulation is a safe, learner centred, educational method that exposes learners to various levels of complexity, similar to real clinical experiences. It creates a learning environment where adjustable levels of challenge are achievable, practice and rehearsal is permitted and corrective feedback is optimised (1).

Simulated patients (SPs) are actors or lay persons trained to portray a particular set of symptoms or roles(2). SP-based communication education allows learners to practise nontechnical skills such as communication, breaking bad news, working with patients in an impaired cognitive state, and disclosing error $(3,4)$. Often trained simulated patients also provide feedback to learners (3). This opportunity adds to the cycle of learning, enabling learners to refine their skills as they learn and develop their communication. Learners often perceive the experience of a SP as more beneficial than other types of learning, such as lectures and reading, and find that the feedback provided to them by the SP is essential to their ability to target specific skills for improvement (5-7). Systematic reviews of simulationbased education report small to moderate patient benefits of technical skills (8), knowledge 
and confidence (9) of the learner, however these skills are practised and refined with highfidelity manikins with or without SPs as part of the education.

With the rising complexity of health care delivery, the importance of good patient-clinician communication has grown exponentially. Several countries around the world have responded by producing policy statements and guidelines emphasising the importance and value of communication education (10). This includes enhancing the experiential dimensions of communication education, through simulation and role-play where shared communication between patients and clinicians becomes the crucial focus of patientcentred care.

While there is a large body of research on the use of manikin-based simulation and SP methodology for teaching clinical skills, the number and quality of papers on the effects of SP-based communication skills training during undergraduate or entry level health professional education is unknown. Therefore, this systematic review aims to critically analyse the existing research investigating whether SP-based communication skills training improves learner-patient communication, how communication skill improvement is measured, and who measures these improvements.

\section{Methods}

This review used the Preferred Reporting Items for Systematic Reviews and Meta-Analyses (PRISMA) guidelines (11). The lead investigator (JK) searched electronic databases Ovid Medline, (Health \& Medical Complete, Nursing and Allied Health Source), and CINAHL (EBSCOhost) Education Resources Information Centre (ERIC) in September 2015. Publications were limited to English and no limitations were placed on date of publication. There were set inclusion and exclusion criteria (Table 1). Boolean operators "AND" and "OR" were used to combine search terms relating to the domains of the PICO (Population, Intervention, Comparison, and Outcomes) model, however the "Comparison" domain was left unlimited to allow for the widest possible search return. Keywords included differences in terminology used to describe tertiary-level education, allied health professions, and 
simulated patients. Truncation markers relevant to each database were used where there were variations in spelling and/or plural forms of search terms. Supplementary File 1 (available online) gives a full list of search terms including MeSH terms, truncations, and Boolean markers.

The removal of duplicates from the search yield occurred and two investigators independently screened all titles and abstracts using Covidence systematic review software (Veritas Health Innovation). Two investigators then independently reviewed the full text publications, with Figure 1 illustrating the reasons for exclusion. Management of conflicts was by discussion between JK and KAB. In the event of indecision, a third author (CW) made the final decision.

All citations of included papers were checked for suitability for inclusion, in addition to checking of all citations of included articles. Articles identified via hand searching were deemed suitable by two authors (JK and KAB), prior to final inclusion. For the purpose of this review, the term "learner" was applied to someone enrolled in a pre-registration undergraduate or post-graduate degree in medicine or a resident, an intern, a clerk, or fellow. Other learners were included if they were enrolled in an undergraduate or postgraduate qualification in nursing or allied health. Training needed to include SP-based activities as part of a curriculum rather than just use within high stakes assessments.

Study quality was assessed using the set of indicators (12). Each indicator was given a score of $0=$ not included/not mentioned, or $1=$ mentioned. Studies meeting a minimum of 7 of the 11 indicators were deemed of a higher quality.

\section{Results}

There were 4,333 studies screened after removed duplicates. Of the 213 remaining articles for full text review, 40 were included and a further 23 found by hand searching. Sixty articles remained for inclusion in the final synthesis (Figure 1). We acknowledge that a large number of articles were found through hand searching and propose that this was due to the vast number of ways "students" and "communication" may be worded in the literature, as well as the variation in SP related terms used by researchers. 
There were 42 studies reporting outcomes for medical learners, 11 for nursing, 10 for allied health, including some studies reporting combinations of professions. There was a mixture of study designs and country of origin, as well as a combination of undergraduate and postgraduate trainees (see Supplementary File 2 online).

The results were initially categorised against outcome measures. Confidence change, effectiveness of training, satisfaction with training and emotional responses to training were the outcome measure groupings determined (Table 2). This collation also recorded who was the primary evaluator of results, the assessor, the learners as a self report and/or the SP. Results were then synthesised against the levels of Kirkpatrick's Hierarchy of Learning and tabulated against Level 1 - Organisational Performance/Patient outcome, Level 2 Behaviour Change, Level 3 - Learning and Level 4 - Reaction(13). Many studies measured across the different levels (Table 2).

\section{LEVEL 4 - Organisational Performance/Patient Outcome.}

Only two studies reported patient outcomes. Jay et al found higher quality counselling skills in residents who had undertaken SP training, as reported by patients (14). Conversely, Curtis (15) found SP training of medical and nursing trainees led to an increase in depressive symptoms of patients who were also palliative. The magnitude of this increase was 2.2 points on a scale ranging over 24 points, as measured with a Patient Health Questionnaire8). The level of experience of the trainees affected this outcome. The magnitude of depression scores was greater when the trainee was a novice. There were no reports on the economic impact or benefit in the use of SP in training.

\section{LEVEL 3 - Behavioural Change}

The majority ( $n=44,73 \%)$ of studies measured some form of learner communication behaviour change with a variety of study designs. These studies engaged the learners themselves, the SP or a third party (i.e. a patient, a lecturer, or a faculty member either external or internal to the research team) to rate communication proficiency $(4,7,14-55)$. Learners were taught the communication skills by a SP and in some studies had a comparator group consisting of lectures, role play, a variation on role play such as theatre 
skills, or both. Extraction of results for meta-analysis was not possible due to the heterogeneity of the data.

Many studies reported statistically significant third party ratings of improved communication effectiveness $(4,17,18,20,33,42,51,53)$ of learners who had trained with a SP. A number of trials with or without randomisation found learners trained with SPs selfreported higher communication effectiveness following SP training $(p<0.05)$. $(4,34,42,51)$. This difference may not have been seen in overall communication domains that were assessed, but were observed in specific communication skills e.g. SP trained learners did better than untrained learners when communicating with a SP specifically about falls $(p=0.04)(51)$. Learners reported behaviour change following SP engagement through semistructured focus groups or through self-rated efficacy scales $(29,30)$. There were a small number of studies comparing SP to no training at all and these did not find any difference between communication skills, contradicting the results from studies reporting benefits. These studies reported that there were few differences in communication skills between learners trained with SP versus no training or training with role play (RP) as assessed by a third party. SP feedback was reported as a helpful tool in consolidating skills (44).

There were very few studies investigating longitudinal maintenance of communication skill development. Only one study reported an immediate positive communication change and tracked this over six months, finding this change was not maintained over this medium term time point (16).

LEVEL 2 - Learning (knowledge)

There were 25 (42\%) studies that incorporated a knowledge change element into the outcome measures $(4,6,14,15,18,20,25-27,33,34,36,37,40,44,50,51,54,56-62)$. Bosse et al studied the difference between SP, RP and no training for the outcome of knowledge gain (20). The SP group demonstrated greater knowledge than the control group $(p<0.05)$ but the RP group had higher third party ratings than SP groups $(p=0.021)$. This was similar to findings by Zavertnik et al (54), where the SP group showed a statistically 
significant improvement in information gathering $(p=-0.0257)$, but no overall knowledge gain as rated by a third party.

LEVEL 1 - Reaction

Lastly, $34(57 \%)$ of the studies gathered information from the learners on their reaction to the use of SP during communication training $(5-7,16,19,21,23,26,27,29,30,35,37,38$, $40,43-46,49,50,56,57,59,60,62-69)$. Overall learners reported satisfaction with training, with one study reporting that although the learners were not looking forward to it, they reported finding the process helpful (30). Turan et al reported no difference in post-test scores between trained and untrained learners $(p>0.05)$, however trained learners reported positive impressions of the SP, and verbally reported that SP training made them feel more prepared to utilise their communication skills in practice (69). Learners also reported that they were more satisfied with their ability to communicate with SPs compared to real patients $(p<0.001)$, and rated their communication skills higher when working with SPs compared to communicating with real patients $(p<0.05)$, however reported the same level of comfort with SPs as with real patients ( $p>0.05)(49)$.

Overall, learners reported statistically significant improvements in their communication skills and confidence following SP training, and commented on the realistic SP portrayals and their intent to use the skills with their patients $(25,37,46,62)$.

\section{Quality assessment}

The number of participants in each included publication ranged from 10 to 472 . Twenty (33\%) of the research studies were randomised and 27 (45\%) studies comparing SP against a control group or another form of education. There were 40 (67\%) studies where the participants self-selected or allocated into the SP group, making the study susceptible to bias. Of the 60 studies included for analysis, 54 (90\%) met the minimum quality score of $7 / 11$ with four articles $(5,7,23,36)(7 \%)$ scoring $11 / 11$. (see Supplementary File 3 online). As there were varied methodologies, a generic quality assessment template was used which 
did not take into account the differences between designs, nor compare all research to the methodological rigour of a randomised control trial.

Overall, there was limited evidence supporting cost-effectiveness, effectiveness of engaging SP's and consequent impact on patient outcomes. SP training may even have a negative effect on patient outcomes when training novice learners. While there was some demonstrated learner behaviour change, there were also results indicating no difference in behaviours of learners who had trained using SP education. Study design rarely allowed longitudinal measurement of this impact or any change over time. SP education resulted in greater learner communication based knowledge gain than learners trained via didactic methods however, these gains were similar to those observed in learners engaged in RP education with peers. Lastly, learner reactions were overall positive in the engagement of SP in education for communication skills.

\section{Discussion}

Some of the findings within this review are in line with those previously published. In the work of Aspegren (70), the author isolated ten measures of communication skills, eight of which were found in the current review. Similarly, Aspegren notes that although specific communication skills can be taught and learned, they are not always retained over time if they are not practised. Retaining the developed communication skill was not commonly measured and this was consistent within this current review. There were also inconsistencies in outcome measures and limited consideration of the long term gain of communication skill and its translation into organisation change and patient outcomes. This review, along with others, revealed a paucity of research into the cost-effectiveness of experiential methods of teaching (70).

Previous research has identified a number of methodological weaknesses, which applied in the current context $(71,72)$. The small sample sizes call into question the generalisability of the results, with some studies in the current review having participant numbers as low as ten. In studies investigating SP-based training and a comparator, no indication was made as 
to whether or not the SP was blinded to the trial condition of the participant. Knowledge of the condition of the learners may have caused the SP to inadvertently act differently towards certain groups of learners. Where studies utilised their own outcome measures, the psychometric properties were rarely mentioned and thus may reduce the validity and reliability of the results. Importantly, little was known about the content of the training, other than the wider subject contexts (e.g. breaking bad news, smoking cessation, counselling, etc). This raises the question of whether training is easier to implement in some contexts than others (72).

As mentioned, studies in this review did not include any form of cost analysis to determine the economic value of SP-based education when compared to the other methods of education (73). SP education was of value to the learner experience and many articles included within this review reported learner satisfaction. However, monetary benefit of selecting SP-based education over another educational approach cannot be fully understood outside of the important but subjective reports of the SP, learner, or third party assessor. In order for a more robust analysis of the benefits of SP-based education, future studies may wish to fill this gap in the knowledge base (73). Furthermore, it is theorised that high-income countries, such as most of the ones in this review, utilise and promote highcost methods of education such as SP-based education $(73,74)$, and this could have impacted the uptake and economic feasibility of these education methods for low-income countries.

There were only two studies measuring the impact of SP-based education on real patient outcomes $(14,15)$. As with all learned skills, it is important to understand the effect on real patients so as to ensure the real-world transferability of the education exercise. The experience of delivering interventions under true clinical conditions is vastly different when compared to the practice that occurs within a safe simulation setting where the experience can be paused, discussed, and re-attempted.

Many of the articles included within the review did not incorporate the level of details to understand the true engagement of the SP with the learner. There was inadequate methodological description to determine if there was time for the SP to feedback to the learner, or the learner to reattempt the communication taught strategy. Therefore it was 
unknown if any of the positive results were in response to methods or the actual SP engagement. Learners with higher patient interaction experience may also mitigate any negative patient outcome in relation to SP-education. This indicates educators should be careful in their choice of the learner target group.

There were limitations to the findings of this present review due to diversity of the SP training interventions, education and outcome measures. This limited the ability to undertake meta-analysis of results and forced a narrative synthesis of results. There is potential that this could have led to inadvertently over emphasising some findings within the results and discussion. Additionally, there was no exclusion of non-randomised control trials, due to the small volume of information left available for review inclusion.

Future research could consider investigating the effects of SP-based communication skills training on real patients in realistic clinical settings. This would also allow for practise of the learned skills, already identified as a missing factor, and re-assessment if necessary to maintain learners' competence. Additionally, there were no longitudinal studies investigating the maintenance of this skill in communication. It is not known if just learning the behaviour will ensure that the behaviour is implemented into practice in an ongoing and meaningful way.

\section{Conclusion}

Simulation education provides learners with a supported learning environment where they can practice a range of clinical skills with the confidence that they can make mistakes and ask questions before being faced with realistic clinical situations. Simulated patients take this realistic learning environment one step further and allow learners to practise skills on real people and receive feedback on their performance, while being encouraged to simultaneously reflect on their own practice.

This review found evidence in support of positive knowledge and behaviour change in learners, but limited support that these changes resulted in different clinical outcomes for patients. The majority of research in the field of communication skills training in SP-based education did not utilise a comparator. There was commonly a lack of outcome measures 
applied to learners as they transitioned into the clinical setting. Learners consider SP-based education valuable as a part of their experience, but the economic benefit of this methodology compared to other forms of education remains largely unknown. There are potentially negative consequences resulting from SP training in the context of delivery of bad news in the palliative care setting.

Future studies should consider randomisation of learners, as well as economic analysis to determine the cost-effectiveness and cost-benefit of such methods of education in the long term.

\section{Acknowledgements}

The authors wish to thank Elizabeth Prior for her contribution in article screening and refining of the question.

\section{Funding}

This research was funded from a "Simulation Patient Safety Research" project funding grant from the Department of Health and Human Services Victoria, Australia (ID3108). TH is funded by a National Health and Medical Research Council Career Research Fellowship, CW is funded by a National Health and Medical Research Council Health Professional Early Career Fellowship.

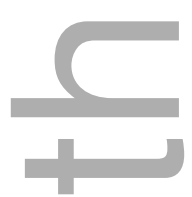

Table 1 Inclusion and Exclusion Criteria

\begin{tabular}{ll}
\hline Inclusion Criteria & Exclusion Criteria \\
\hline Outcome measures reported & No abstract \\
Learners as participants & Literature reviews \\
English & Electronic/computer/virtual simulation \\
Trained person or actor as SP to & Studies investigating inter-professional \\
\hline
\end{tabular}

This article is protected by copyright. All rights reserved 
achieve outcome

Person centred communication skills as outcome

Peer-reviewed publication

Intervention incorporating face-to-

face education and/or feedback

from SP

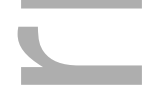

()

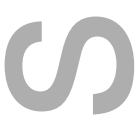

(2)

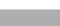
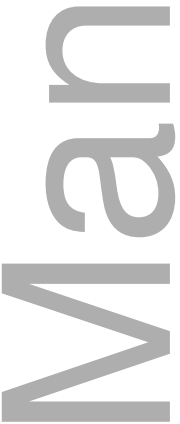

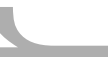

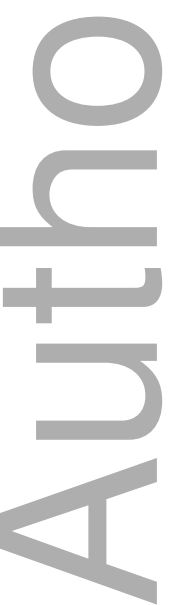

communication

Studies with SPs in team-building exercises

Studies evaluating linguistics or language without

person-centred outcome measures

Study design including SP as part of the

assessment only (i.e.: SP for an examination of

theory or technical skill)

Full text not available 
Table 2: Reported outcome measure categories, and who rated the outcome

\begin{tabular}{|c|c|c|c|c|c|c|c|c|c|c|c|c|c|}
\hline \multirow{2}{*}{ Author } & \multicolumn{3}{|c|}{$\begin{array}{c}\text { Confidence } \\
\text { change }\end{array}$} & \multicolumn{3}{|c|}{$\begin{array}{l}\text { Effectiveness of } \\
\text { training }\end{array}$} & \multicolumn{3}{|c|}{$\begin{array}{l}\text { Satisfaction with } \\
\text { training }\end{array}$} & \multicolumn{3}{|c|}{$\begin{array}{l}\text { Emotional } \\
\text { response to } \\
\text { training }\end{array}$} & \multirow{2}{*}{$\begin{array}{c}\text { Kirkpatrick's } \\
\text { Hierarchy of } \\
\text { Learning } \\
\text { Level/s }\end{array}$} \\
\hline & Self & SP & $3^{\text {rd }}$ & Self & SP & $3^{\text {rd }}$ & Self & SP & $3^{\text {rd }}$ & Self & SP & $3^{\text {rd }}$ & \\
\hline Alexandera \& Dearsley, 2013(63) & $\checkmark$ & & & & & & & & & $\checkmark$ & & & 4 \\
\hline Anderson et al, 2014 (4) & & & & & $\checkmark$ & $\checkmark$ & $\checkmark$ & & & & & & 2,3 \\
\hline Bachmann et al, 2003 (56) & & & & & & $\checkmark$ & $\checkmark$ & & $\checkmark$ & & & & 3,4 \\
\hline Back et al, 2007 (17) & & & & & $x$ & $\checkmark$ & & & & & & & 2 \\
\hline Bays et al, 2014 (18) & & & & & & $\checkmark$ & & & & & & & 2,3 \\
\hline Becker et al, 2006 (57) & & & & $\checkmark$ & $\checkmark$ & $\checkmark$ & $\checkmark$ & & & $\checkmark$ & & & 3,4 \\
\hline Bokken et al, 2009 (19) & & & & $\checkmark$ & & & $\checkmark$ & & & & & & 2,4 \\
\hline Bonnaud-Antignac et al, 2010 & & & & $\checkmark$ & & $\checkmark$ & & & & & & & 4 \\
\hline (64) & & & & & & & & & & & & & \\
\hline Bosse et al, $2012(20)$ & & & & $\checkmark$ & & & & & & & & & 2,3 \\
\hline Brame et al, 2012 (16) & $\checkmark$ & & & & & & & & & & & & 2,4 \\
\hline Buckman et al, 1997 (21) & & & & $\checkmark$ & & & & & & $\checkmark$ & & & 2,4 \\
\hline Carroll et al, 1981 (58) & & & & $\checkmark$ & $\checkmark$ & $\checkmark$ & & & & & & & 3 \\
\hline Childers et al, 2012 (59) & $\checkmark$ & & & & & $\checkmark$ & & & & $\checkmark$ & & & 3,4 \\
\hline Chur-Hansen, 2001 (22) & & & & $\checkmark$ & & $\checkmark$ & & & & & & & 2 \\
\hline Clayton et al, 2013 (23) & $\checkmark$ & & & $\checkmark$ & & $\checkmark$ & $\checkmark$ & & & $\checkmark$ & & & 2,4 \\
\hline Colletti et al, 2001 (24) & & & & & $\checkmark$ & & & & & & & & 2 \\
\hline Curtis et al, 2013 (15) & & & & & & $\checkmark$ & & & & & & & $1,2,3$ \\
\hline Dikici et al, 2009(25) & & & & $\checkmark$ & & & $\checkmark$ & & & & & & 2,3 \\
\hline Downar et al, 2012 (26) & & & & $\checkmark$ & $\checkmark$ & $\checkmark$ & $\checkmark$ & & & & & & $2,3,4$ \\
\hline Eagles et al, $2001(6)$ & & & & $\checkmark$ & & & $\checkmark$ & & & $\checkmark$ & & & 3,4 \\
\hline Elley et al, 2012 (27) & $\checkmark$ & & & & & & & & & & & & $2,3,4$ \\
\hline Elman et al, 2004 (28) & & & & & & $\checkmark$ & & & & & & & 2 \\
\hline Felton et al, 2013 (29) & & & & $\checkmark$ & & & & & & & & & 2,4 \\
\hline Fiedorowicz et al, 2013 (30) & & & & $\checkmark$ & & & $\checkmark$ & & & & & & 2,4 \\
\hline Fortin et al, 2002 (60) & & & & $\checkmark$ & & & & & & & & & 3,4 \\
\hline Gallagher, 1999 (31) & & & & $\checkmark$ & $\checkmark$ & & $\checkmark$ & & & $\checkmark$ & & & 2 \\
\hline Gibson \& Davidson, 2015 (32) & & & & $\checkmark$ & & $\checkmark$ & & & & & & & 2 \\
\hline Greenberg et al, 1999 (33) & & & & & $\checkmark$ & & & & & & & & 2,3 \\
\hline Haist et al, 2003 (34) & & & & $\checkmark$ & $\checkmark$ & $\checkmark$ & & & & & & & 2,3 \\
\hline Hale et al, 2006 (7) & & & & $\checkmark$ & & $\checkmark$ & $\checkmark$ & & & $\checkmark$ & $\checkmark$ & & 2,4 \\
\hline Halkett et al, 2011 (65) & $\checkmark$ & & & & & & $\checkmark$ & & & & & & 4 \\
\hline Haracz et al, 2015 (35) & $\checkmark$ & & & $\checkmark$ & & & $\checkmark$ & & & & & & 2,4 \\
\hline Henry et al, 2009 (61) & & & & $\checkmark$ & & & $\checkmark$ & & & $\checkmark$ & & & 3,4 \\
\hline Hurst et al, 2015 (66) & $\checkmark$ & & & $\checkmark$ & & & & & & $\checkmark$ & & & 4 \\
\hline Jay et al, $2010(14)$ & & & & & & $\checkmark$ & & & & & & & $1,2,3$ \\
\hline Koponen et al, 2011 (5) & & & & & & & $\checkmark$ & & & $\checkmark$ & & & 4 \\
\hline Koponen et al, 2014 (36) & & & & & & & & & & $\checkmark$ & & & 2,3 \\
\hline Layat Burn et al, 2014 (37) & & & & $\checkmark$ & & & & & & $\checkmark$ & & & $2,3,4$ \\
\hline Lewis et al, 2008 (67) & $\checkmark$ & & & & & & & & & & & & 4 \\
\hline Lin et al, 2013 (38) & & & & $\checkmark$ & & $\checkmark$ & $\checkmark$ & & & & & & 2,4 \\
\hline
\end{tabular}




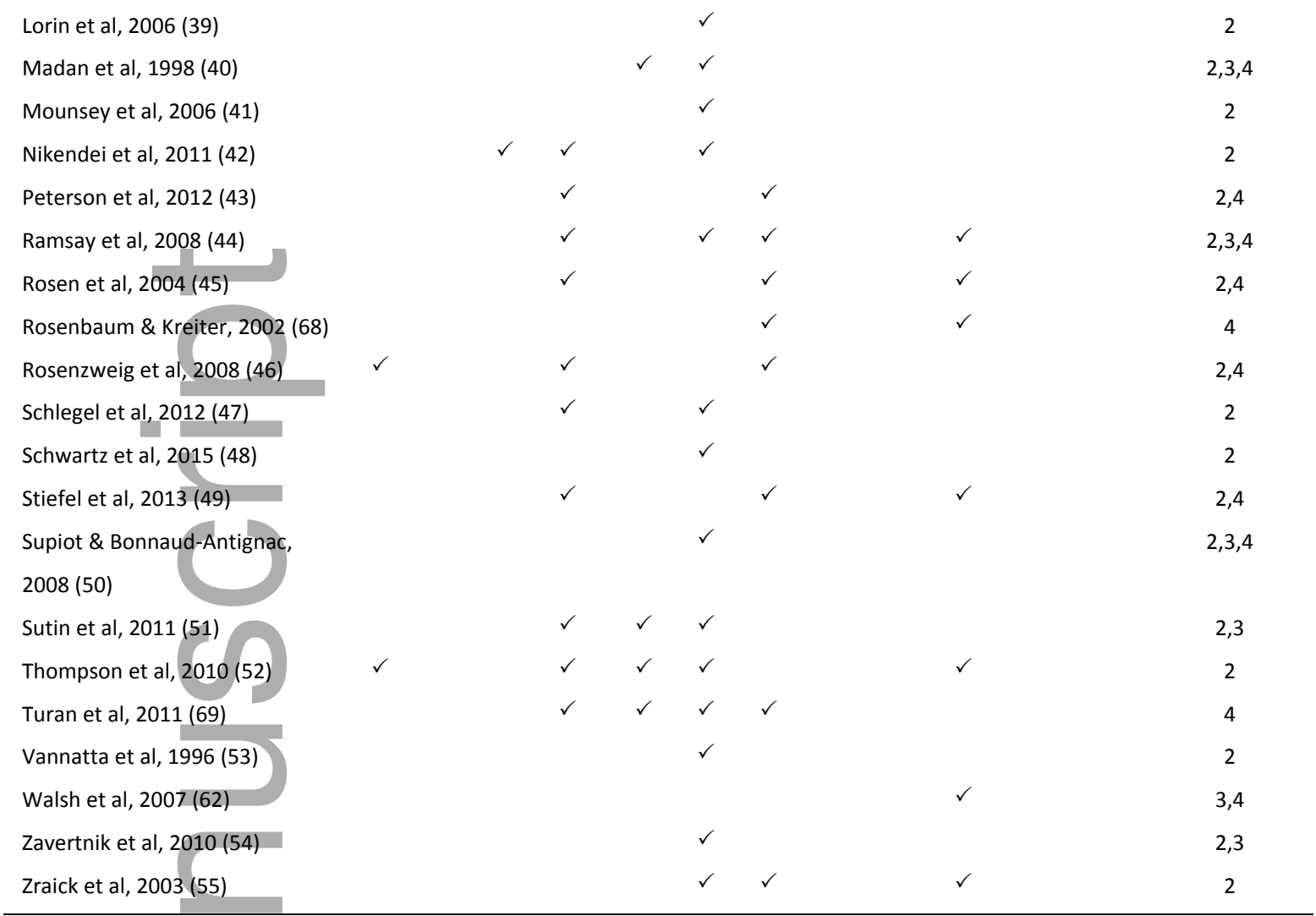

Self - Self Rater, SP - Simulated patient rater, $3^{\text {rd }}-$ Third party rater

\section{References}

1. Schmidt E, Goldhaber-Fiebert SN, Ho LA, McDonald KM. Simulation exercises as a patient safety strategy: a systematic review. Ann Int Med. 2013;158(5_Part_2):426-32.

2. Nestel D, Burn CL, Pritchard SA, Glastonbury R, Tabak D. The use of simulated patients in medical education: Guide supplement 42.1 - Viewpoint. Medical Teacher. 2011;33(12):1027-9.

3. Bokken L, van Dalen J, Rethans J-J. The case of "Miss Jacobs": adolescent simulated patients and the quality of their role playing, feedback, and personal impact. Simul Healthc. 2010;5(6):315-9. 4. Anderson HA, Young J, Marrelli D, Black R, Lambreghts K, Twa MD. Training students with patient actors improves communication: a pilot study. 2014.

5. Koponen J, Pyörälä E, Isotalus P. A comparison of medical students' perceptions of three experiential methods. Health Education. 2011;111(4):296-318.

6. Eagles JM, Calder SA, Nicoll KS, Walker LG. A comparison of real patients, simulated patients and videotaped interview in teaching medical students about alcohol misuse. Medical teacher. 2001;23(5):490-3. 
7. Hale LS, Lewis DK, Eckert RM, Wilson CM, Smith BS. Standardized patients and multidisciplinary classroom instruction for physical therapist students to improve interviewing skills and attitudes about diabetes. Journal of Physical Therapy Education. 2006;20(1):22-7.

8. Zendejas B, Brydges R, Wang AT, Cook DA. Patient Outcomes in Simulation-Based Medical Education: A Systematic Review. J Gen Intern Med. 2013;28(8):1078-89.

9. Boling B, Hardin-Pierce M. The effect of high-fidelity simulation on knowledge and confidence in critical care training: An integrative review. Nurse Education in Practice. 2016;16(1):287-93.

10. Ledema R, Manidis M. Patient-clinician communication: An overview of relevant research and policy literatures. In: Science MaH, editor. Sydney: Australian Commission on Safety and Quality in Health Care and UTS Centre for Health Communication; 2013. p. 1-208.

11. Liberati A, Altman DG, Tetzlaff J, Mulrow C, Gøtzsche PC, loannidis JP, et al. The PRISMA statement for reporting systematic reviews and meta-analyses of studies that evaluate health care interventions: explanation and elaboration. Annals of internal medicine. 2009;151(4):W-65-W-94. 12. Buckley S, Coleman J, Davidson I, Khan KS, Zamora J, Malick S, et al. The educational effects of portfolios on undergraduate student learning: A Best Evidence Medical Education (BEME) systematic review. BEME Guide No. 11. Medical Teacher. 2009;31(4):282-98.

13. Kirkpatrick D, Kirkpatrick J. Transferring learning to behavior: Using the four levels to improve performance: Berrett-Koehler Publishers; 2005.

14. Jay M, Schlair S, Caldwell R, Kalet A, Sherman S, Gillespie C. From the Patient's Perspective: The Impact of Training on Resident Physician's Obesity Counseling. J Gen Intern Med. 2010;25(5):415-22.

15. Curtis JR, Back AL, Ford DW, Downey L, Shannon SE, Doorenbos AZ, et al. Effect of communication skills training for residents and nurse practitioners on quality of communication with patients with serious illness: a randomized trial. Jama. 2013;310(21):2271-81.

16. Brame JL, Martin R, Tavoc T, Stein M, Curran AE. A randomized controlled trial of the effect of standardized patient scenarios on dental hygiene students' confidence in providing tobacco dependence counseling. J Dent Hyg. 2012;86(4):282-91.

17. Back AL, Arnold RM, Baile WF, Fryer-Edwards KA, et al. Efficacy of Communication Skills Training for Giving Bad News and Discussing Transitions to Palliative Care. Archives of Internal Medicine. 2007;167(5):453-60.

18. Bays AM, Engelberg RA, Back AL, Ford DW, Downey L, Shannon SE, et al. Interprofessional Communication Skills Training for Serious Illness: Evaluation of a Small-Group, Simulated Patient Intervention. Journal of palliative medicine. 2014;17(2):159-66. 
19. Bokken L, Rethans J-J, van Heurn L, Duvivier R, Scherpbier A, van der Vleuten C. Students' views on the use of real patients and simulated patients in undergraduate medical education. Academic medicine : journal of the Association of American Medical Colleges. 2009;84(7):958-63. 20. Bosse HM, Schultz JH, Nickel M, Lutz T, Möltner A, Jünger J, et al. The effect of using standardized patients or peer role play on ratings of undergraduate communication training: $A$ randomized controlled trial. Patient Education \& Counseling. 2012;87(3):300-6.

21. Buckman R, Kason Y, Garg A. Teaching medical students how to break bad news. Canadian Medical Association Journal. 1997;156(8):1159-64.

22. Chur-Hansen A. The Self-Evaluation of Medical Communication Skills. Higher Education Research \& Development. 2001;20(1):71-9.

23. Clayton JM, Butow PN, Waters A, Laidsaar-Powell RC, O'Brien A, Boyle F, et al. Evaluation of a novel individualised communication-skills training intervention to improve doctors' confidence and skills in end-of-life communication. Palliative medicine. 2013;27(3):236-43.

24. Colletti L, Gruppen L, Barclay M, Stern D. Teaching students to break bad news. American journal of surgery. 2001;182(1):20-3.

25. Dikici MF, Yaris F, Cubukcu M. Teaching medical students how to break bad news: a Turkish experience. Journal of Cancer Education. 2009;24(4):246-8.

26. Downar J, Knickle K, Granton JT, Hawryluck L. Using standardized family members to teach communication skills and ethical principles to critical care trainees. Critical care medicine. 2012;40(6):1814-9.

27. Elley CR, Clinick T, Wong C, Arroll B, Kennelly J, Doerr H, et al. Effectiveness of simulated clinical teaching in general practice: randomised controlled trial. Journal of Primary Health Care. 2012;4(4):281-7.

28. Elman D, Hooks R, Tabak D, Regehr G, Freeman R. The effectiveness of unannounced standardised patients in the clinical setting as a teaching intervention. Medical education. 2004;38(9):969-73.

29. Felton A, Holliday L, Ritchie D, Langmack G, Conquer A. Simulation: A shared learning experience for child and mental health pre-registration nursing students. Nurse education in practice. 2013;13(6):536-40.

30. Fiedorowicz JG, Tate J, Miller AC, Franklin EM, Gourley R, Rosenbaum M. A medical interviewing curriculum intervention for medical students' assessment of suicide risk. 2013.

31. Gallagher TH, Pantilat SZ, Lo B, Papadakis MA. Teaching medical students to discuss advance directives: A standardized patient curriculum. Teaching and Learning in Medicine. 1999;11(3):142-7. 
32. Gibson SJ, Davidson ZE. An observational study investigating the impact of simulated patients in teaching communication skills in preclinical dietetic students. Journal of Human Nutrition and Dietetics. 2015.

33. Greenberg LW, Pedreira F, Getson P, Brasseux C. Teaching telephone management skills to pediatric residents in a pilot program using a standardized patient. Southern medical journal. 1999;92(4):394-9.

34. Haist SA, Wilson JF, Pursley HG, Jessup ML, Gibson JS, Kwolek DG, et al. Domestic violence: Increasing knowledge and improving skills with a four-hour workshop using standardized patients. Academic Medicine. 2003;78(10):S24-S6.

35. Haracz K, Arrighi G, Joyce B. Simulated patients in a mental health occupational therapy course: A pilot study. British Journal of Occupational Therapy. 2015:0308022614562792.

36. Koponen J, Pyörälä E, Isotalus P. Communication Skills for Medical Students Results From Three Experiential Methods. Simulation \& Gaming. 2014;45(2):235-54.

37. Layat Burn C, Hurst SA, Ummel M, Cerutti B, Baroffio A. Telling the truth: medical students' progress with an ethical skill. Medical teacher. 2014;36(3):251-9.

38. Lin EC-L, Chen S-L, Chao S-Y, Chen Y-C. Using standardized patient with immediate feedback and group discussion to teach interpersonal and communication skills to advanced practice nursing students. Nurse education today. 2013;33(6):677-83.

39. Lorin S, Rho L, Wisnivesky JP, Nierman DM. Improving medical student intensive care unit communication skills: a novel educational initiative using standardized family members. Critical Care Medicine. 2006;34(9):2386-91.

40. Madan AK, Caruso BA, Lopes JE, Gracely EJ. Comparison of simulated patient and didactic methods of teaching HIV risk assessment to medical residents. American journal of preventive medicine. 1998;15(2):114-9.

41. Mounsey AL, Bovbjerg V, White L, Gazewood J. Do students develop better motivational interviewing skills through role-play with standardised patients or with student colleagues? Medical Education. 2006;40(8):775-80.

42. Nikendei C, Bosse HM, Hoffmann K, Möltner A, Hancke R, Conrad C, et al. Outcome of parent-physician communication skills training for pediatric residents. Patient education and counseling. 2011;82(1):94-9.

43. Peterson EB, Porter MB, Calhoun AW. A simulation-based curriculum to address relational crises in medicine. Journal of graduate medical education. 2012;4(3):351-6.

44. Ramsay J, Keith G, Ker JS, Hogg G. Use of simulated patients for a communication skills exercise. Nursing Standard. 2008;22(19):39-44. 
45. Rosen J, Spatz ES, Gaaserud AMJ, Abramovitch H, Weinreb B, Wenger NS, et al. A new approach to developing cross-cultural communication skills. Medical Teacher. 2004;26(2):126-32.

46. Rosenzweig M, Hravnak M, Magdic K, Beach M, Clifton M, Arnold R. Patient communication simulation laboratory for students in an acute care nurse practitioner program. American Journal of Critical Care. 2008;17(4):364-72.

47. Schlegel CMMERN, Woermann UMDMME, Shaha MPRN, Rethans J-JMDP, van der Vleuten CP. Effects of Communication Training on Real Practice Performance: A Role-Play Module Versus a Standardized Patient Module. Journal of Nursing Education. 2012;51(1):16-22.

48. Schwartz VS, Rothpletz-Puglia P, Denmark R, Byham-Gray L. Comparison of standardized patients and real patients as an experiential teaching strategy in a nutrition counseling course for dietetic students. Patient Education \& Counseling. 2015;98(2):168-73.

49. Stiefel F, Bourquin C, Layat C, Vadot S, Bonvin R, Berney A. Medical students' skills and needs for training in breaking bad news. Journal of Cancer Education. 2013;28(1):187-91.

50. Supiot S, Bonnaud-Antignac A. Using simulated interviews to teach junior medical students to disclose the diagnosis of cancer. Journal of Cancer Education. 2008;23(2):102-7.

51. Sutin D, Rolita L, Yeboah N, Taffel L, Zabar S. A Novel Longitudinal Geriatric Medical Student Experience: Using Teaching Objective Structured Clinical Examinations. Journal of the American Geriatrics Society. 2011;59(9):1739-44.

52. Thompson BM, Teal CR, Scott SM, Manning SN, Greenfield E, Shada R, et al. Following the clues: teaching medical students to explore patients' contexts. Patient Education \& Counseling. 2010;80(3):345-50.

53. Vannatta JB, Smith KR, Crandall S, Fischer PC, Williams K. Comparison of standardized patients and faculty in teaching medical interviewing. Academic Medicine. 1996;71(12):1360-2. 54. Zavertnik JE, Huff TA, Munro CL. Innovative approach to teaching communication skills to nursing students. Journal of Nursing Education. 2010;49(2):65-71.

55. Zraick RI, Allen RM, Johnson SB. The use of standardized patients to teach and test interpersonal and communication skills with students in speech-language pathology. Advances in health sciences education : theory and practice. 2003;8(3):237-48.

56. Bachmann C, Barzel A, Roschlaub S, Ehrhardt M, Scherer M. Can a brief two-hour interdisciplinary communication skills training be successful in undergraduate medical education? Patient Education and Counseling. 2013;93(2):298-305.

57. Becker KLMSC, Rose LEP, Berg JBMSABC, Park HMPHRN, Shatzer JHP. The Teaching Effectiveness of Standardized Patients. Journal of Nursing Education. 2006;45(4):103-11. 
58. Carroll GJ. An Evaluation of Simulated Patients as Instructors: Implications for Teaching Medical Interview Skills. Journal of Medical Education. 1981;56(6):522-4.

59. Childers JW, Bost JE, Kraemer KL, Cluss PA, Spagnoletti CL, Gonzaga AM, et al. Giving residents tools to talk about behavior change: A motivational interviewing curriculum description and evaluation. Patient Education \& Counseling. 2012;89(2):281-7.

60. Fortin AHMDMPH, Haeseler FDMD, Angoff NMDMPHM, Cariaga-lo LP, Ellman MSMD, Vasquez LMD, et al. Teaching pre-clinical medical students an integrated approach to medical interviewing. J Gen Intern Med. 2002;17(9):704-8.

61. Henry BW, Duellman MC, Smith TJ. Nutrition-Based Standardized Patient Sessions Increased Counseling Awareness and Confidence Among Dietetic Interns. Topics in Clinical Nutrition. 2009;24(1):25-34.

62. Walsh SE, Singleton JA, Worth CT, Krugler J, Moore R, Wesley GC, et al. Tobacco cessation counseling training with standardized patients. J Dent Educ. 2007;71(9):1171-8.

63. Alexandera L, Dearsley A. Using standardized patients in an undergraduate mental health simulation: A pilot study. International Journal of Mental Health. 2013;42(2-3):149-64.

64. Bonnaud-Antignac A, Campion L, Pottier P, Supiot S. Videotaped simulated interviews to improve medical students' skills in disclosing a diagnosis of cancer. Psycho-oncology. 2010;19(9):975-81.

65. Halkett GK, McKay J, Shaw T. Improving students' confidence levels in communicating with patients and introducing students to the importance of history taking. Radiography. 2011;17(1):5560.

66. Hurst SA, Baroffio A, Ummel M, Burn CL. Helping medical students to acquire a deeper understanding of truth-telling. Medical education online. 2015;20.

67. Lewis M, Bell J, Asghar A. Use of simulated patients in development of physiotherapy students' interpersonal skills. International Journal of Therapy \& Rehabilitation. 2008;15(5):221-7. 68. Rosenbaum ME, Kreiter C. Teaching delivery of bad news using experiential sessions with standardized patients. Teaching and learning in medicine. 2002;14(3):144-9.

69. Turan S, Uner S, Elcin M. The impact of standardized patient feedback on student motivational levels. Balkan Medical Journal. 2011;28(1):43-8.

70. Aspegren K. BEME Guide No. 2: Teaching and learning communication skills in medicine - a review with quality grading of articles. Medical Teacher. 1999;21(6):563-70.

71. Lane C, Rollnick S. The use of simulated patients and role-play in communication skills training: a review of the literature to August 2005. Patient Education \& Counseling. 2007;67(1-2):1320. 
72. Berkhof M, van Rijssen HJ, Schellart AJM, Anema JR, van der Beek AJ. Effective training strategies for teaching communication skills to physicians: an overview of systematic reviews. Patient education and counseling. 2011;84(2):152-62.

73. Maloney S, Haines T. Issues of cost-benefit and cost-effectiveness for simulation in health professions education. Advances in Simulation. 2016;1(1):1.

74. Maloney S, Walsh K, llic D, Rivers GS, Osadnik CR. Cost and Sustainability of Respiratory Medicine Education in Low-Income Countries. Annals of the American Thoracic Society. 2016;13(9):1664-5.

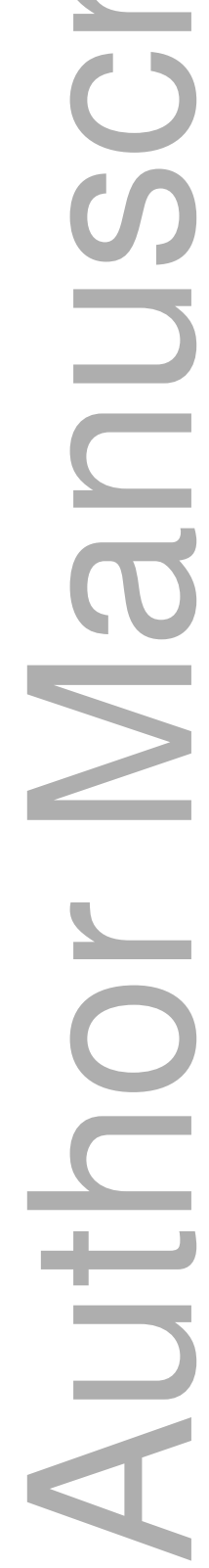


Figure 1 - Prisma chart of included articles
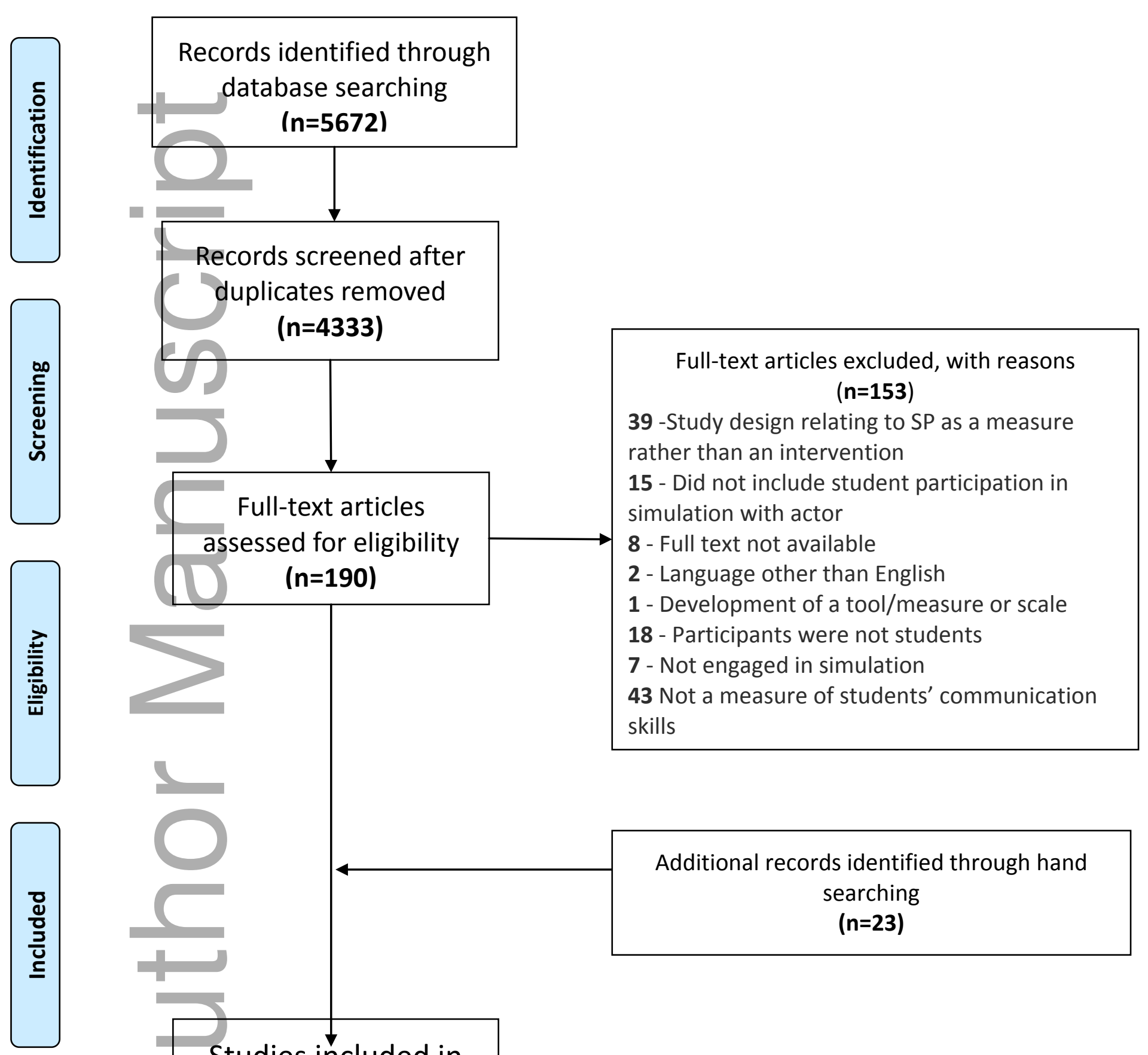


\section{University Library}

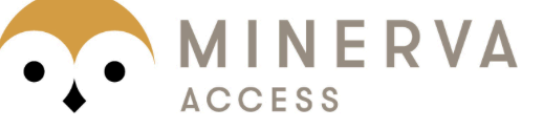

A gateway to Melbourne's research publications

Minerva Access is the Institutional Repository of The University of Melbourne

Author/s:

Kaplonyi, J;Bowles, K-A;Nestel, D;Kiegaldie, D;Maloney, S;Haines, T;Williams, C

Title:

Understanding the impact of simulated patients on health care learners' communication skills: a systematic review

Date:

2017-12-01

Citation:

Kaplonyi, J., Bowles, K. -A., Nestel, D., Kiegaldie, D., Maloney, S., Haines, T. \& Williams, C. (2017). Understanding the impact of simulated patients on health care learners' communication skills: a systematic review. MEDICAL EDUCATION, 51 (12), pp.1209-1219. https://doi.org/10.1111/medu.13387.

Persistent Link:

http://hdl.handle.net/11343/293338 